\title{
AN INTERESTING CASE OF DIABETIC MUSCLE INFARCTION
}

\author{
N. Srichandhanreddy ${ }^{1}$, Jagadish ${ }^{2}$, Suresh ${ }^{3}$, Venkata Rathnamma P. N ${ }^{4}$
}

\section{HOW TO CITE THIS ARTICLE:}

N. Srichandhanreddy, Jagadish, Suresh, Venkata Rathnamma P. N. "An Interesting case of Diabetic Muscle Infarction". Journal of Evolution of Medical and Dental Sciences 2014; Vol. 3, Issue 34, August 11;

Page: 9081-9085, DOI: 10.14260/jemds/2014/3171

ABSTRACT: Diabetic muscle infarction is rare complications of diabetes that occurs in patients with type 1 diabetes (70\% of total cases) or in patients with poorly controlled type 2 diabetes. Here is a 55 year old male patient was admitted with diabetic ketoacidosis and coma. Two days later following recovery he gave history of pain in the right thigh since 10 days. There was no history of trauma, fever, weight loss. On examination vitals are stable, systemic examination: clinically normal. Examination of right thigh lower one third, showed a tender mass of about 3.4 x8.2 cms, FNAC of which showed muscle fibres with hemorrhagic back ground. MRI scan suggesting of myositis involving vastus group of muscles. This patient had normal renal functions and normal fundus. This patient responded to conservative management and antibiotics. CONCLUSION: A high index of suspicion is needed to make a timely diagnosis of diabetic muscle Infarction, and avoid the use of steroids or surgical intervention.

KEYWORDS: A high index of suspicion is needed to make a timely diagnosis of diabetic muscle Infarction, and avoid the use of steroids or surgical intervention

INTRODUCTION: Diabetic muscle infarction was first described in 1965 by Angervall and Stener as tumoriform focal muscular degeneration. Like other long-term complications of diabetes, diabetic myopathy is believed to be secondary to a microvascular pathologic process, with inflammation, ischemia, and infarction of the affected muscle. Now a day's diabetes is more common in many people, as the diabetic muscle infarction is a rare complication. This case is reported in order to make a timely diagnosis of diabetic muscle Infarction, and avoid the use of steroids or surgical intervention.

CASE REPORT: A 55 year old male patient who is a known case of diabetes mellitus and hypertensive since 10 years was admitted with diabetic ketoacidosis and coma. Loss of consciousness for 1 day, he did not take his diabetic treatment for 5 days Two days later following recovery he gave history of pain in the right thigh since 10 days. There was no history of trauma, fever, weight loss. On examination vitals are stable, systemic examination: clinically normal. Examination of right thigh lower one third, showed a tender mass of about $3.4 \times 8.2 \mathrm{cms}$,

\section{INVESTIGATIONS:}

- FNAC showed muscle fibres with hemorrhagic back ground.

- MRI scan: Diffuse altered signal intensities involving entire vastus medialis muscle, medial aspect of rectus femoris and distal aspect of vastus lateralis of quadriceps femoris suggestive of myositis involving vastus group of muscles.

- This patient had normal renal functions and normal fundus.

- This patient responded to conservative management and antibiotics. 


\section{CASE REPORT}

Figure 1and figure 2: MRI of thigh muscles showing diabetic muscle infarction.

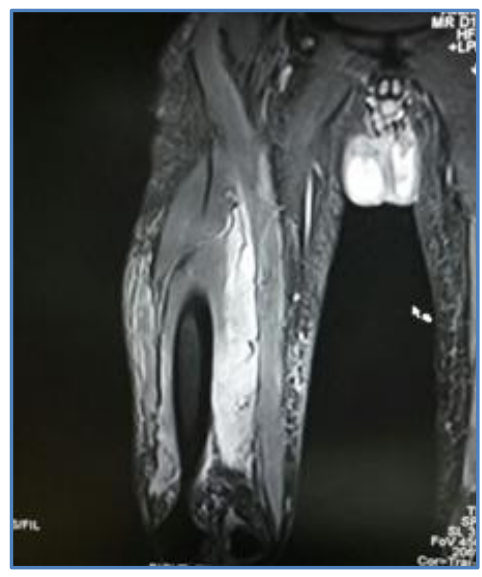

Fig. 1

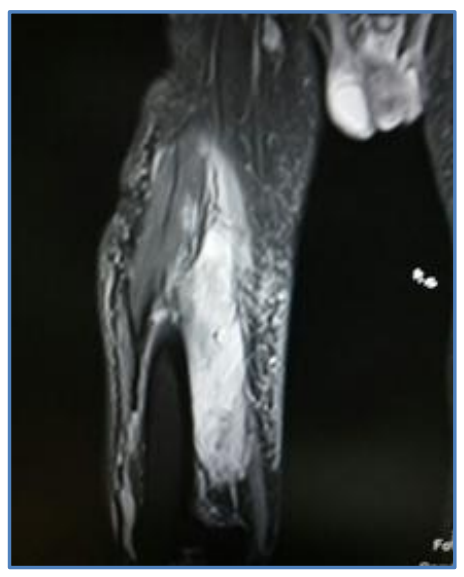

Fig. 2

Figure 3: Microphotograph showing degenerated muscle fibres and inflammatory cells. (H\&E stain)

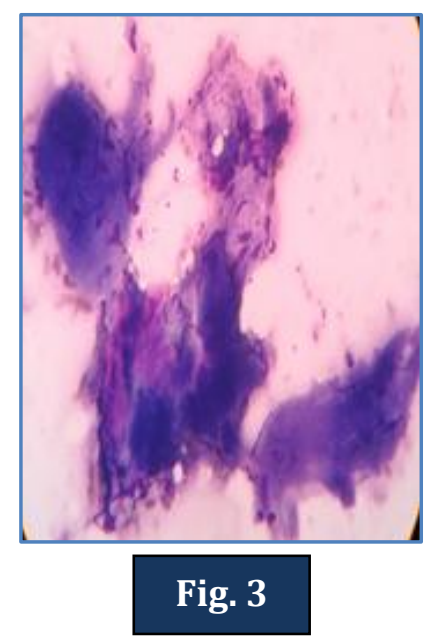

Figure 4: Microphotograph showing muscle fibres against hemorrhagic background.

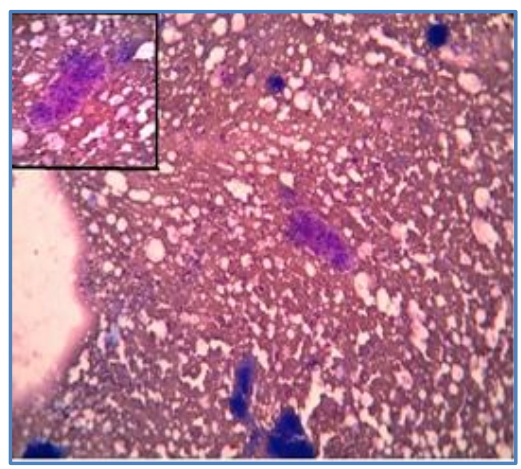

Fig. 4 


\section{CASE REPORT}

\section{DISCUSSION:}

- Most common complications of diabetes are vasculopathy, neuropathy, nephropathy and retinopathy.

- DMI is a rare complication, it presents as an acute, localized, exquisitely painful mass, with swelling and limited range of motion of the extremity. It persists for a few weeks, and there are no systemic signs of infection.

- It is difficult to diagnose based on history and imaging because of its rarity. ${ }^{1}$

- DMI usually occurs mostly in patients with microvascular and macrovascular omplications. ${ }^{2}$

- Usual age of presentation of DMI is average is 40 years, ranges between 13-81 years.3,4

- DMI occurs more in women, rare in men. ${ }^{5}$

- Vascular conditions ex. deep venous thrombosis and infections are considered in the differential diagnosis.

- The localized nature of the condition and the absence of distal edema or involvement of the lower portions of the limb will help in the diagnosis. Vascular studies may be necessary to diagnose deep venous thrombosis.

- Primary hemorrhage into the muscle presents with a localized, painful mass, mimics DMI requires imaging studies to differentiate.

- Pseudothrombophlebitis presents as a painful, swollen limb, with history of arthritis, trauma, or recent exertion, and a palpable cyst.

- In arterial occlusion, there may be absence of distal pulses with skin changes.

- A history of blunt trauma or recent strenuous activity can differentiate contusion, muscle strain or posttraumatic false aneurysm.

- Cellulitis, pyomyositis, soft tissue abscess are seen in patients who are on insulin, are differentiated based on the skin changes.

- Inflammatory myositis presents as a painful swelling of the extremity but creatine kinase elevations and proximal muscle weakness indicates the appropriate diagnosis.

- Neurologic syndromes begin with an abrupt onset of lower extremity pain that ultimately will involve the opposite side. The pain is usually localized to the low back and buttocks and with dramatic weakness and atrophy of the muscles.

- Treatment is by analgesics and activity restriction in the acute phase, followed by gentle physical therapy until the symptoms subside.

- Patients usually recover spontaneously over a period of weeks to months without the need for surgical debridement.

- The recurrence rate in the same or the contralateral extremity is approximately $40 \% .6,7$

- Rarely patients might not improve with this regimen and will benefit from surgical resection.

- Patients having terminal diabetic nephropathy are prone to develop diabetic muscle infarction and nearly one-fourth of diabetic muscle infarction patients receive renal replacement treatment. 8

- We reviewed the literature and discussed 48 episodes of diabetes mellitus in 30 patients with chronic kidney disease.9-11 
CONCLUSION: A high index of suspicion is needed to make a timely diagnosis of diabetic muscle Infarction, and avoid the use of steroids or surgical intervention

\section{REFERENCES:}

1. Aboulafia AJ, Monson DK, Kennon RE. Clinical and radiological aspects of idiopathic diabetic muscle infarction. Rational approach to diagnosis and treatment. J Bone Joint Surg. (B) 1999; 81: 323-326.

2. Grigoriadis E, Fam AG, Starok M, Ang LC. Skeletal muscle infarction in diabetes mellitus.Journal of Rheumatology. 2000; 27 (4):1063-1068.

3. Badalov N, Baradarian R, Iswara K, Li J, Steinberg W, Tenner S. Drug-induced acute pancreatitis: an evidence-based review. Clin Gastroenterol Hepatol. 2007; 5 (6): 648-661.

4. Kapur S, McKendry RJ. Treatment and outcomes of diabetic muscle infarction. Journal of Clinical Rheumatology. 2005; 11 (1): 8-12.

5. Umeukeje J, Pletcher BA, Blacksin M, Sharer LR, Wenger P, Singer-Granick C. Muscle infarction in a 13 year-old female with type 1 diabetes mellitus of short duration. Journal of Pediatric Endocrinology and Metabolism. 2006; 19 (8): 1039-1043..

6. Joshi R, Reen B, Sheehan H. Upper extremity diabetic muscle infarction in three patients with end-stage renal disease: a case series and review. Journal of Clinical Rheumatology.2009; 15 (2): 81-84.

7. Umpierrez GE, Stiles RG, Kleinbart J, Krendel DA, Watts NB. Diabetic muscle infarction. American Journal of Medicine. 1996; 101 (3): 245-250.

8. Kapur S, Brunet JA, McKendry RJ. Diabetic muscle infarction: case report and review. Journal of Rheumatology. 2004; 31 (1): 190-194.

9. N Melikian, J Bingham, D J A Goldsmith. Diabetic muscle infarction: an unusual cause of acute limb swelling in patients on hemodialysis. American Journal of Kidney Diseases, vol. 41, no. 6, pp. 1322-1326, 2003.

10. E Theodoropoulou, E Chelioti, K Revenas, N Katsilambros, A Kostakis, J N Boletis. Diabetic muscle infarction after kidney and pancreas transplanation: case report and literature review. Transplantation Proceedings, vol. 38, no. 9, pp. 3147-3150, 2006.

11. S Delis, G Ciancio, J Casillas et al. Diabetic muscle infarction after simultaneous pancreas-kidney transplant. Clinical Transplantation, vol. 16, no. 4, pp. 295-300, 2002.

12. K L Lentine, S S Guest. Diabetic muscle infarction in end-stage renal disease. Nephrology Dialysis Transplantation, vol. 19, no. 3, pp. 664-669, 2004. 


\section{CASE REPORT}

\section{AUTHORS:}

1. N. Srichandhanreddy

2. Jagadish

3. Suresh

4. Venkata Rathnamma P. N.

\section{PARTICULARS OF CONTRIBUTORS:}

1. Post Graduate, Department of General Medicine, Sri Devaraj Urs Medical College in General Medicine.

2. Professor, Department of Radiology, Sri Devaraj Urs Medical College.

3. Professor, Department of Pathology, Sri Devaraj Urs Medical College

4. Professor, Department of Medicine, Sri Devaraj Urs Medical College.

\section{NAME ADDRESS EMAIL ID OF THE}

\section{CORRESPONDING AUTHOR:}

Dr. Srichandhanreddy,

PG Mens Block,

Room No. 202,

Sri Devaraj Urs Medical College,

Tamaka, Kolar-563101,

Karnataka, India.

Email: srichandhanreddy@gmail.com

Date of Submission: 08/07/2014.

Date of Peer Review: 09/07/2014.

Date of Acceptance: 05/08/2014.

Date of Publishing: 11/08/2014. 